\title{
Impact of the presence of heart disease, cardiovascular medications and cardiac events on outcome in COVID-19
}

\author{
Gonzalo Cabezón Villalba ${ }^{1} \oplus$, Ignacio J. Amat-Santos ${ }^{1,2}$, Carlos Dueñas ${ }^{3}$,

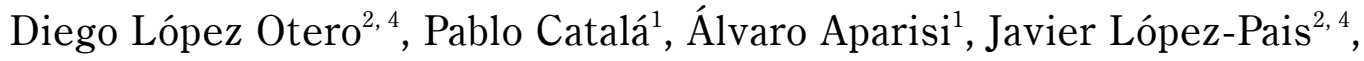 \\ Carla Eugenia Cacho Antonio ${ }^{4}$, Jordi Candela ${ }^{1}$, Pablo Antúnez Muiños ${ }^{4}$, \\ José Francisco Gil ${ }^{1}$, Teba González Ferrero ${ }^{4}$, Marta Marcos ${ }^{1}$, Marta Pérez-Poza ${ }^{4}$, \\ Gino Rojas ${ }^{1}$, Oscar Otero García ${ }^{4}$, Carlos Veras ${ }^{1}$, Víctor Jiménez Ramos ${ }^{4}$, \\ Aitor Uribarri ${ }^{1,2}$, Ana Revilla ${ }^{1,2}$, Pablo Elpidio García-Granja ${ }^{1,2}$, Itzíar Gómez ${ }^{1,2}$, \\ José Ramón González-Juanatey ${ }^{2,4}$, J. Alberto San Román ${ }^{1,2}$ (D) \\ ${ }^{1}$ Cardiology Department, Hospital Clínico Universitario, Valladolid, Spain \\ ${ }^{2}$ Centro de Investigación Biomédica en Red - Cardiovascular (CIBER-CV), Spain \\ ${ }^{3}$ Department of Infectious Diseases, Hospital Clínico Universitario, Valladolid, Spain \\ ${ }^{4}$ Cardiology Department, Hospital Clínico Universitario, Santiago de Compostela, Spain
}

\begin{abstract}
Background: Cardiovascular risk factors and usage of cardiovascular medication are prevalent among coronavirus disease 2019 (COVID-19) patients. Little is known about the cardiovascular implications of COVID-19. The goal herein, was to evaluate the prognostic impact of having heart disease (HD) and taking cardiovascular medications in a population diagnosed of COVID-19 who required hospitalization. Also, we studied the development of cardiovascular events during hospitalization.

Methods: Consecutive patients with definitive diagnosis of COVID-19 made by a positive real time-polymerase chain reaction of nasopharyngeal swabs who were admitted to the hospital from March 15 to April 14 were included in a retrospective registry. The association of HD with mortality and with mortality or respiratory failure were the primary and secondary objectives, respectively.

Results: A total of 859 patients were included in the present analysis. Cardiovascular risk factors were related to death, particularly diabetes mellitus (hazard ratio in the multivariate analysis: 1.810 [1.159-2.827], $p=0.009)$. A total of $113(13.1 \%)$ patients had HD. The presence of HD identified a group of patients with higher mortality $(35.4 \%$ vs. $18.2 \%, p<0.001)$ but HD was not independently related to prognosis; renin-angiotensin-aldosterone system inhibitors, calcium channel blockers, diuretics and beta-blockers did not worsen prognosis. Statins were independently associated with decreased mortality (0.551 [0.329-0.921], $p=0.023$ ). Cardiovascular events during hospitalization identified a group of patients with poor outcome (mortality $31.8 \%$ vs. $19.3 \%$ without cardiovascular events, $p=0.007$ ).

Conclusions: The presence of HD is related to higher mortality. Cardiovascular medications taken before admission are not harmful, statins being protective. The development of cardiovascular events during the course of the disease is related to poor outcome. (Cardiol J 2021; 28, 3: 360-368)

Key words: COVID-19, heart failure, statins, diabetes mellitus, cardiovascular diseases
\end{abstract}

Address for correspondence: Dr. J. Alberto San Roman, Department of Cardiology, Institute of Heart Sciences (ICICOR), Hospital Clínico Universitario, Valladolid, Spain, e-mail: asanroman@secardiologia.es

Received: 7.10.2020 Accepted: 25.02.2021

This article is available in open access under Creative Common Attribution-Non-Commercial-No Derivatives 4.0 International (CC BY-NC-ND 4.0) license, allowing to download articles and share them with others as long as they credit the authors and the publisher, but without permission to change them in any way or use them commercially. 


\section{Introduction}

On Thursday, December $12^{\text {th }}$, some people who had visited the Huanan Seafood Market were found to present viral pneumonia, later labeled by the World Health Organization as coronavirus disease 2019 (COVID-19). Since then, the outbreak which has changed our lives forever has infected more than 100 million people around the world carrying a mortality of approximately $2 \%$ [1]. Comorbidities, which have a clear impact on prognosis, are frequent in patients with severe COVID-19 [2-5]. Zhou et al. [6] have seen that $86 \%$ of patients who presented coronary artery disease died. In a series of 487 patients, cardiovascular diseases were more frequent in patients who died $(8.2 \%$ vs. $1.6 \%$ ) but only age, male gender and hypertension independently predicted death [7]. Besides, the term "cardiovascular diseases" was not defined.

Viral infections can contribute to acute coronary syndromes both by a direct effect on an atherosclerotic plaque inducing inflammation in the endothelium and smooth muscle cells, or by an indirect effect causing a hyperinflammatory stage with elevated pro-inflammatory cytokines, which may elicit plaque rupture of a coronary artery [8-11]. While some investigations have dealt with the impact of myocardial injury [12] or ischemic heart disease [13] on the outcome of patients with COVID-19, little is known about other types of heart disease (HD) like valvular disease or other cardiomyopathies.

The impact of HD and outcome has not been studied in other diseases with many similarities to COVID-19, the Middle East respiratory syndrome and the severe acute respiratory syndrome. Eventually, if patients with HD have worse outcomes than other patients, public health policies should be designed to target those patients as a priority group for vaccination against the severe acute respiratory syndrome coronavirus 2 (SARS-CoV-2).

Furthermore, the prognostic consequences of taking cardiovascular medications are undetermined. While some authors warn about the harmful effect of renin-angiotensin-aldosterone system (RAAS) blockers and advise its discontinuation to prevent poor outcome [14] others advocate maintaining these drugs until more evidence is available [15]. There is little information concerning statins.

In addition, cardiovascular events could occur during the course of the disease, such as myocardial infarction, decompensated heart failure, myocarditis and others. Nonetheless, the rate, and impact on outcome of different cardiovascular events are far from clear.
Keeping in mind this background, we have assessed the cardiovascular implications of COVID-19. Thus, the present study investigated the prognostic impact of having HD and taking cardiovascular medications in a well characterized population diagnosed of COVID-19 who required hospitalization. In addition, the development of cardiovascular events during hospitalization was also studied.

\section{Methods}

This is an observational and retrospective multicenter study with a total of 210 variables per patient gathered in a specific database from data prospectively collected from the electronic medical records. All consecutive non-selected patients with definitive diagnosis of COVID-19 made by a positive real time-polymerase chain reaction of nasopharyngeal swabs who were admitted to two tertiary hospitals from March 15 to April 14 were included. No exclusion criteria were considered. Follow-up after discharge from hospital was not performed.

A descriptive analysis of heart related characteristics of a COVID-19 population was carried out. Association of HD with mortality and the composite of mortality or respiratory failure were the primary and secondary objectives, respectively.

Data recorded at admission covered epidemiological, clinical, laboratory (complete blood count, coagulation testing including D-dimer, iron metabolism including ferritin, electrolytes, assessment of liver and renal function, C-reactive protein, erythrocyte sedimentation rate, lactate dehydrogenase, procalcitonin and creatine kinase), electrocardiogram (ECG) when available, and chest-X ray parameters. Computed tomography scan was performed when indicated by the physician in charge of the patient. Interpretation of chest imaging tests were performed by an expert radiologist. Troponin and interleukin- 6 were obtained at the discretion of the physician. The study was approved by the local ethics committee.

\section{Definitions}

Ischemic heart disease comprised patients with a previous diagnostic angiography, previous myocardial infarction and patients with no anatomical confirmation but symptoms compatible and, at least, one noninvasive positive test for ischemia. Valvular heart disease was diagnosed when the patient had moderate or severe dysfunction of at least one valve. Cardiovascular events were defined as 
follows: heart failure, pericarditis and myocarditis were defined according to the corresponding guidelines of the European Society of Cardiology [16-18]; acute myocardial infarction was diagnosed when the patient presented compatible chest pain, ST changes and elevation of troponin. Isolated elevation of troponin was considered as myocardial injury but not as an infarction. Atrial fibrillation was regarded as an event when it appeared during hospitalization. Respiratory failure was defined as $\mathrm{pO}_{2}<60 \mathrm{mmHg}$ or $\mathrm{SatO}_{2}<90 \%$ without oxygen support at any moment of the patient's hospitalization. Azithromycin, hydroxychloroquine and lopinavir-ritonavir were considered drugs that may cause QT interval prolongation.

\section{Statistical analysis}

Categorical variables were reported as absolute values and percentages. Continuous variables were reported as the mean \pm standard deviation or median and interquartile range. Normal distribution of quantitative variables were verified with the Kolmogorov-Smirnov test. Categorical variables were compared with the $\chi^{2}$ test and the Fisher exact test. Continuous variables were compared with the Student $t$ test or its equivalent for nonparametric tests, the Mann-Whitney U test was used for variables that were not normally distributed.

To identify factors that were predictive of mortality and the composite endpoint (mortality or respiratory failure), a logistic regression model with the maximum likelihood method was constructed by using backward stepwise selection, which included the variables that were statistically significant in the univariate analysis. No more than 1 variable per 10 outcome events was entered in the logistic model to avoid overfitting. For the final model we calculated odds ratios adjusted for each of the variables included, along with their 95\% confidence intervals. Goodness of fit for each model was determined with the Hosmer-Lemeshow test and $\mathrm{C}$-index.

All data were entered into a database and analyzed with version 15.0 of the Statistical Package for Social Sciences (SPSS Inc., Chicago, IL). Differences were considered statistically significant when $\mathrm{p}$ was $<0.05$.

\section{Results}

\section{Characteristics of the patients}

A total of 859 patients made up the present study group. Main characteristics of patients are shown in Table 1 . Mean age was 68 years and
$49.5 \%$ were female $(\mathrm{n}=425)$. Among comorbid conditions, $49.5 \%$ presented arterial hypertension, $19.3 \%$ diabetes mellitus, $40.5 \%$ dyslipidemia, $9.3 \%$ chronic obstructive pulmonary disease (COPD) and $6.9 \%$ chronic kidney disease (CKD). A total of $20.5 \%$ patients died $(n=176)$.

Heart disease was present in 113 (13.1\%) patients (Table 2). The most frequent was ischemic HD with 71 patients; 34 patients had valvular HD and 14 cardiomyopathy; 6 patients presented more than one.

Comparison of patients with and without $\mathrm{HD}$ Patients with HD were older and presented higher rates of arterial hypertension, diabetes mellitus, dyslipidemia and CKD as shown in Table 1. Regarding laboratory data, HD patients had more lymphopenia, anemia, higher values of creatinine, D-dimer and procalcitonin. Sinus rhythm was more frequent in patients without HD. Patients with HD suffered more respiratory failure and death.

\section{Predictors of outcome}

Multivariate analysis for predictors of death was performed, included in the model were all variables that were significant in the univariate analysis, namely: age, hypertension, diabetes mellitus, CKD, presence of HD, COPD, dyslipidemia, lymphocyte count $<1000 / \mathrm{mm}^{3}$, D-dimer $>500 \mu \mathrm{g} / \mathrm{L}$, C-reactive protein (CRP) $>10 \mathrm{mg} / \mathrm{mL}$ and hemoglobin $<10 \mathrm{mg} / \mathrm{dL}$. As can be seen in Table 3, age, diabetes mellitus, COPD, lymphocyte count $<1000 / \mathrm{mm}^{3}$ and CRP $>10 \mathrm{mg} / \mathrm{L}$ were independently associated with mortality. HD was strongly associated with mortality, but was not an independent predictor of death.

For the composite endpoint (respiratory failure and death), variables predictive in the univariate analysis were age, hypertension, diabetes mellitus, CKD, presence of HD, lymphocyte count $<1000$ / $/ \mathrm{mm}^{3}, \mathrm{D}$-dimer $>500 \mu \mathrm{g} / \mathrm{L}, \mathrm{CRP}>10 \mathrm{mg} / \mathrm{mL}$ and hemoglobin $<10 \mathrm{mg} / \mathrm{dL}$. Independent predictors of the composite endpoint after multivariate analysis were age, diabetes mellitus, CKD, low lymphocyte count, high D-dimer, high CRP. Again, HD was not independently related to the composite endpoint.

\section{Medications at admission and mortality}

Table 4 shows the mortality rate of patients according to the medications taken at admission. Univariate and multivariate analysis of composite endpoint according to medication are depicted in Table 5. Angiotensin converting enzyme (ACE) inhibitors, angiotensin receptor blockers and 
Table 1. Main characteristics of the overall population and comparison between patients with heart disease (HD) and without HD.

\begin{tabular}{|c|c|c|c|c|}
\hline & $\begin{array}{c}\text { Total } \\
(n=859)\end{array}$ & $\begin{array}{l}\text { With HD } \\
(n=113)\end{array}$ & $\begin{array}{l}\text { Without HD } \\
(\mathrm{n}=746)\end{array}$ & $\mathbf{P}$ \\
\hline Mean age & 68.1 & 75.6 & 67.0 & $<0.001$ \\
\hline Female & $425(49.5 \%)$ & $50(44.2 \%)$ & $375(50.2 \%)$ & 0.233 \\
\hline \multicolumn{5}{|l|}{ Comorbidities } \\
\hline Hypertension & $425(49.5 \%)$ & $86(76.1 \%)$ & $339(45.4 \%)$ & $<0.001$ \\
\hline Diabetes mellitus & $166(19.3 \%)$ & $43(38.1 \%)$ & $123(16.5 \%)$ & $<0.001$ \\
\hline Chronic kidney disease & $59(6.9 \%)$ & $16(14.2 \%)$ & $43(5.8 \%)$ & $<0.001$ \\
\hline Dyslipidemia & $348(40.5 \%)$ & $79(69.9 \%)$ & $269(36.1 \%)$ & $<0.001$ \\
\hline Current smoker & $36(4.2 \%)$ & $3(2.7 \%)$ & $33(4.4 \%)$ & 0.612 \\
\hline Chronic obstructive pulmonary disease & $79(9.3 \%)$ & $15(13.3 \%)$ & $64(8.7 \%)$ & 0.120 \\
\hline \multicolumn{5}{|l|}{ Clinical picture } \\
\hline Temperature $>37.5^{\circ}$ & $627(73.0 \%)$ & $81(71.7 \%)$ & $546(73.2 \%)$ & 0.753 \\
\hline Cough & $581(67.6 \%)$ & $61(54.0 \%)$ & $520(69.7 \%)$ & 0.001 \\
\hline Dyspnea & $402(46.8 \%)$ & $55(48.7 \%)$ & $347(46.5 \%)$ & 0.668 \\
\hline Diarrhea & $182(21.2 \%)$ & $22(19.5 \%)$ & $160(21.4 \%)$ & 0.631 \\
\hline \multicolumn{5}{|l|}{ Blood analysis } \\
\hline Leukocytes $>10.000 / \mathrm{mm}^{3}$ & $136(15.9 \%)$ & $24(21.6 \%)$ & $112(15.0 \%)$ & 0.076 \\
\hline Leukocytes $<4.000 / \mathrm{mm}^{3}$ & $137(16.0 \%)$ & $21(18.9 \%)$ & $116(15.6 \%)$ & 0.368 \\
\hline Lymphocytes $<1.000 / \mathrm{mm}^{3}$ & $478(55.6 \%)$ & $76(67.0 \%)$ & $402(53.9 \%)$ & 0.010 \\
\hline Hemoglobin $<10 \mathrm{~g} / \mathrm{dL}$ & $52(6.1 \%)$ & $15(13.4 \%)$ & $37(5.0 \%)$ & 0.001 \\
\hline Platelets $<150.000 / \mathrm{mm}^{3}$ & $210(24.5 \%)$ & $35(31.2 \%)$ & $175(23.5 \%)$ & 0.076 \\
\hline Aspartate aminotransferase $>40 \mathrm{U} / \mathrm{L}$ & $356(41.4 \%)$ & $53(46.9 \%)$ & $303(40.5 \%)$ & 0.230 \\
\hline Alanine aminotransferase $>40 \mathrm{U} / \mathrm{L}$ & $311(36.2 \%)$ & $41(36.1 \%)$ & $270(36.2 \%)$ & 0.991 \\
\hline Lactate dehydrogenase $>250 \mathrm{U} / \mathrm{L}$ & $564(65.7 \%)$ & $78(69.4 \%)$ & $486(65.2 \%)$ & 0.415 \\
\hline D-dimer $>500 \mu \mathrm{g} / \mathrm{L}$ & $620(72.2 \%)$ & $92(81.1 \%)$ & $528(70.8 \%)$ & 0.027 \\
\hline Creatinine $>1.5 \mathrm{mg} / \mathrm{dL}$ & $119(13.9 \%)$ & $31(27.7 \%)$ & $88(11.8 \%)$ & $<0.001$ \\
\hline C-reactive protein $>10 \mathrm{mg} / \mathrm{L}$ & $618(71.9 \%)$ & $83(73.4 \%)$ & $535(71.7 \%)$ & 0.711 \\
\hline Procalcitonin $>0.5 \mathrm{ng} / \mathrm{mL}$ & $126(14.7 \%)$ & $26(22.8 \%)$ & $100(13.6 \%)$ & 0.019 \\
\hline \multicolumn{5}{|l|}{ Chest-X ray } \\
\hline Abnormal & $799(93.0 \%)$ & $104(92.0 \%)$ & $695(93.2 \%)$ & 0.664 \\
\hline Local opacity/shadowing & $421(40.9 \%)$ & $42(37.6 \%)$ & $379(41.4 \%)$ & 0.472 \\
\hline Diffuse/bilateral shadowing/opacity & $559(65.1 \%)$ & $76(67.0 \%)$ & $483(64.9 \%)$ & 0.671 \\
\hline Interstitial pattern & $140(16.3 \%)$ & $19(17.2 \%)$ & $121(16.1 \%)$ & 0.793 \\
\hline Alveolointerstitial pattern & $367(42.7 \%)$ & $46(40.6 \%)$ & $321(43.0 \%)$ & 0.651 \\
\hline \multicolumn{5}{|l|}{ Electrocardiogram } \\
\hline Sinus rhythm & $760(88.5 \%)$ & $83(73.3 \%)$ & $677(90.6 \%)$ & $<0.001$ \\
\hline \multicolumn{5}{|l|}{ Clinical evolution } \\
\hline In-hospital death & $176(20.5 \%)$ & $40(35.4 \%)$ & $136(18.2 \%)$ & $<0.001$ \\
\hline Respiratory failure & $350(40.8 \%)$ & $64(56.4 \%)$ & $286(38.5 \%)$ & $<0.001$ \\
\hline Mechanical ventilation & $73(8.5 \%)$ & $8(7.1 \%)$ & $65(8.7 \%)$ & 0.562 \\
\hline Heart failure & $67(7.8 \%)$ & $19(16.8 \%)$ & $48(6.4 \%)$ & 0.001 \\
\hline
\end{tabular}

beta-blockers were not independent predictors of death. However, statins were independently associated to better prognosis after multivariate analysis.

\section{Clinical course}

During hospitalization 85 patients developed cardiovascular events (Table 6), 24 of them (28.2\%) had history of HD. The development of cardio- 
Table 2. Characterization of the 113 patients with heart disease.

\begin{tabular}{lcc}
\hline Condition & N & Mortality \\
\hline Ischemic heart disease & $71(63 \%)$ & $25(35.2 \%)$ \\
Previous myocardial infarction & 49 & $17(34.7 \%)$ \\
Percutaneous revascularization: & 56 & $20(35.7 \%)$ \\
One vessel & 35 & $13(37.1 \%)$ \\
Two vessels & 13 & $4(30.8 \%)$ \\
Three vessels & 8 & $3(37.5 \%)$ \\
Left anterior descending artery & 36 & $13(36.1 \%)$ \\
Surgical revascularization & 4 & $0(0 \%)$ \\
Valvular heart disease & $34(30 \%)$ & $14(41 \%)$ \\
Mitral regurgitation & 11 & $5(45 \%)$ \\
Mitral stenosis & 0 & - \\
Aortic regurgitation & 5 & $1(20 \%)$ \\
Aortic stenosis & 12 & $6(50 \%)$ \\
Prosthesis & 5 & $1(20 \%)$ \\
Other & 5 & $1(20 \%)$ \\
Cardiomyopathy & $14(12 \%)$ & $6(43 \%)$ \\
Dilated & 10 & $4(40 \%)$ \\
Hypertrophic & 4 & $2(50 \%)$ \\
\hline
\end{tabular}

Table 4. Crude mortality rate according to the medications taken at admission

\begin{tabular}{lcc}
\hline & N & Mortality \\
\hline $\begin{array}{l}\text { Angiotensin converting } \\
\text { enzyme inhibitors }\end{array}$ & 147 & $36(24.5 \%)$ \\
Angiotensin receptor blockers & 176 & $49(27.8 \%)$ \\
Beta-blockers & 158 & $57(36.1 \%)$ \\
Calcium antagonists & 82 & $28(34.1 \%)$ \\
Diuretics & 130 & $51(39.2 \%)$ \\
Statins & 295 & $66(22.4 \%)$ \\
Acetylsalicylic acid & 131 & $43(32.8 \%)$ \\
Antivitamin K & 94 & $42(44.7 \%)$ \\
Direct oral anticoagulants & 31 & $18(58.1 \%)$ \\
\hline
\end{tabular}

vascular events during hospitalization identified a group of patients with poor outcome (mortality $31.8 \%$ vs. $19.3 \%$ in patients without cardiovascular events, $\mathrm{p}=0.007$ ). Acute heart failure was the most frequent cardiovascular event $(\mathrm{n}=64)$ and was associated with increased mortality $(32.8 \%$ vs. $16.6 \%, \mathrm{p}>0.001)$.

Table 3. Predictors of mortality and the composite endpoint.

\begin{tabular}{|c|c|c|c|c|}
\hline \multirow[t]{2}{*}{ Variable } & \multicolumn{2}{|c|}{ Univariate } & \multicolumn{2}{|c|}{ Multivariate } \\
\hline & OR (95\% Cl) & $\mathbf{P}$ & OR (95\% CI) & $\mathbf{P}$ \\
\hline \multicolumn{5}{|l|}{ Mortality } \\
\hline Age & $1.093(1.074-1.111)$ & $<0.001$ & $1.076(1.057-1.095)$ & $<0.001$ \\
\hline Hypertension & $2.928(2.052-4.179)$ & $<0.001$ & & \\
\hline Diabetes mellitus & 2.715 (1.866-3.949) & $<0.001$ & $1.810(1.159-2.827)$ & 0.009 \\
\hline Chronic kidney disease & $4.294(2.500-7.375)$ & $<0.001$ & $1.882(0.984-3.601)$ & 0.056 \\
\hline Heart disease & $2.458(1.602-3.771)$ & $<0.001$ & & \\
\hline COPD & $2.296(1.402-3.759)$ & 0.001 & $1.787(1.004-3.182)$ & 0.048 \\
\hline Dyslipidemia & 1.675 (1.200-2.338) & 0.002 & & \\
\hline Lymphocytes < 1000/m³ & $2.350(1.638-3.371)$ & $<0.001$ & $1.692(1.111-2.577)$ & 0.014 \\
\hline D-dimer $>500 \mu \mathrm{g} / \mathrm{L}$ & $2.388(1.522-3.747)$ & $<0.001$ & & \\
\hline C-reactive protein $>10 \mathrm{mg} / \mathrm{L}$ & $3.383(2.083-5.492)$ & $<0.001$ & $2.786(1.639-4.734)$ & $<0.001$ \\
\hline Hemoglobin $<10 \mathrm{~g} / \mathrm{dL}$ & $4.000(2.257-7.089)$ & $<0.001$ & & \\
\hline \multicolumn{5}{|l|}{ Mortality + respiratory failure } \\
\hline Age & $1.045(1.034-1.056)$ & $<0.001$ & $1.029(1.017-1.041)$ & $<0.001$ \\
\hline Hypertension & $2.047(1.556-2.692)$ & $<0.001$ & & \\
\hline Diabetes mellitus & $2.664(1.877-3.782)$ & $<0.001$ & $2.173(1.459-3.236)$ & $<0.001$ \\
\hline Chronic kidney disease & $4.114(2.252-7.515)$ & $<0.001$ & $2.617(1.331-5.144)$ & 0.005 \\
\hline Heart disease & $2.230(1.487-3.344)$ & $<0.001$ & & \\
\hline Lymphocytes < 1000/m³ & $2.534(1.911-3.361)$ & $<0.001$ & $2.074(1.509-2.849)$ & $<0.001$ \\
\hline D-dimer $>500 \mu \mathrm{g} / \mathrm{L}$ & $2.191(1.582-3.035)$ & $<0.001$ & $1.523(1.061-2.186)$ & 0.023 \\
\hline C-reactive protein $>10 \mathrm{mg} / \mathrm{L}$ & $3.434(2.445-4.824)$ & $<0.001$ & $3.160(2.189-4.559)$ & $<0.001$ \\
\hline Hemoglobin $<10 \mathrm{~g} / \mathrm{dL}$ & $3.357(1.813-6.216)$ & $<0.001$ & & \\
\hline
\end{tabular}

$\mathrm{Cl}$ — confidence interval; COPD — chronic obstructive pulmonary disease; OR - odds ratio 
Table 5. Univariate and multivariate analysis of mortality according to medication.

\begin{tabular}{|c|c|c|c|c|}
\hline \multirow[t]{2}{*}{ Variable } & \multicolumn{2}{|c|}{ Univariate } & \multicolumn{2}{|c|}{ Multivariate } \\
\hline & OR (95\% Cl) & $\mathbf{P}$ & OR (95\% CI) & $\mathbf{P}$ \\
\hline Age & $1.093(1.074-1.111)$ & $<0.001$ & $1.079(1.060-1.099)$ & $<0.001$ \\
\hline Hypertension & $2.928(2.052-4.179)$ & $<0.001$ & & \\
\hline Diabetes mellitus & $2.715(1.866-3.949)$ & $<0.001$ & $1.886(1.181-3.012)$ & 0.008 \\
\hline Chronic kidney disease & $4.294(2.500-7.375)$ & $<0.001$ & & \\
\hline Heart disease & $2.458(1.602-3.771)$ & $<0.001$ & & \\
\hline COPD & $2.296(1.402-3.759)$ & 0.001 & $1.817(1.005-3.287)$ & 0.048 \\
\hline Dyslipidemia & $1.675(1.200-2.338)$ & 0.002 & $1.651(0.996-2.736)$ & 0.052 \\
\hline Lymphocytes $<1000 / \mathrm{m}^{3}$ & $2.350(1.638-3.371)$ & $<0.001$ & $1.668(1.088-2.526)$ & 0.019 \\
\hline D-dimer $>500 \mu \mathrm{g} / \mathrm{L}$ & $2.388(1.522-3.747)$ & $<0.001$ & & \\
\hline C-reactive protein $>10 \mathrm{mg} / \mathrm{L}$ & $3.383(2.083-5.492)$ & $<0.001$ & $2.741(1.610-4.666)$ & $<0.001$ \\
\hline Hemoglobin $<10 \mathrm{~g} / \mathrm{dL}$ & $4.000(2.257-7.089)$ & $<0.001$ & $2.376(1.145-4.931)$ & 0.020 \\
\hline ACE inhibitor & $1.325(0.871-2.016)$ & $<0.188$ & & \\
\hline Angiotensin receptor blocker & $1.691(1.154-2.480)$ & 0.007 & & \\
\hline Beta-blockers & $2.750(1.880-4.023)$ & $<0.001$ & & \\
\hline Statins & $1.156(0.816-1.628)$ & 0.419 & $0.551(0.329-0.921)$ & 0.023 \\
\hline
\end{tabular}

$\mathrm{ACE}$ - angiotensin convertin enzyme; $\mathrm{Cl}$ — confidence interval; $\mathrm{COPD}$ - chronic obstructive pulmonary disease; OR — odds ratio

Table 6. Cardiovascular events during hospital stay. Several patients had more than one event.

\begin{tabular}{lcc}
\hline Cardiovascular event & N (\%) & Mortality \\
\hline Heart failure & $64(7.4 \%)$ & $21(33 \%)$ \\
$\begin{array}{l}\text { Acute myocardial } \\
\text { infarction }\end{array}$ & $4(0.4 \%)$ & $0(0 \%)$ \\
Pericarditis & $3(0.3 \%)$ & $1(33 \%)$ \\
Myocarditis & $2(0.2 \%)$ & $1(50 \%)$ \\
Atrial fibrillation & $12(1.4 \%)$ & $3(25 \%)$ \\
Ventricular tachycardia & $1(0.1 \%)$ & $1(100 \%)$ \\
or sudden cardiac death & & $1(25 \%)$ \\
Other cardiovascular & $4(0.4 \%)$ & \\
events & & \\
TOTAL & $90(10.5 \%)$ & \\
\hline
\end{tabular}

\section{Electrocardiogram}

Electrocardiogram was performed in 485 (57.9\%) patients. Only $50.8 \%$ of patients admitted in March had an ECG available (308 of 606) but this percentage rose to $65.8 \%$ (166 of 252) in April. In patients with ECG performed QTc was measured in $52.8 \%(\mathrm{n}=256)$ and QT interval lengthening (longer than $440 \mathrm{~ms}$ in men and $460 \mathrm{~ms}$ in women) was found in $16(6.3 \%)$ patients. Of the 353 patients without ECG, 326 (92.3\%) took, at least, one medication which lengthens the QT interval and $304(86.1 \%)$ at least two.

\section{Discussion}

This study regarding hospitalized patients with COVID-19 had the goal to examine specific cardiovascular aspects, and several findings have to be underlined: 1) cardiovascular risk factors are common in COVID-19 and entail poor prognosis, particularly diabetes mellitus; 2 ) the presence of $\mathrm{HD}$ identifies a group of patients with poor outcome; HD is not independently related to prognosis, though; 3) cardiovascular medications normally used are not harmful, and statins may be protective; 4) cardiovascular events are frequent and negatively impact on prognosis. All these assertions not only emphasize the close relationship between COVID-19 and the heart but also highlight the importance of cardiologists being part of the multidisciplinary team taking care of these patients.

Cardiovascular risk factors are frequent in COVID-19 patients. Diabetes mellitus is as frequent as $20 \%$ [12], hypertension 30\% [4] and active smoking $12.6 \%$ [3]. Surprisingly, dyslipidemia was not reported in any of the series. In the current cohort, the prevalence of these risk factors is even greater. Importantly, diabetes mellitus was a very powerful predictor of death in the current series, in line with previous publications [19].

Several physiopathologic mechanisms have been proposed to explain the poor prognosis in dia- 
betic patients with COVID-19, linked to increased ACE2, furin and interleukin-6 levels [20, 21].

There are multiple mechanisms proposed to explain the association between $\mathrm{HD}$ and poor outcome in COVID-19. Patients in the present study with HD show more anemia, higher levels of D-dimer and procalcitonin and worse renal function, which suggests that the worse clinical evolution of these patients may be related to an aggressive hyperinflammatory and prothrombotic response and to a deficient immune response as suggested by the lower levels of lymphocytes.

Despite HD, it did not constitute an independent predictor of death in the population study, the current work shows that the presence of HD identifies a high-risk population and is a marker of poor outcome in COVID-19. Therefore, intensive surveillance and precocious treatment could be beneficial in this population. Public health policies should target those patients as a priority group for the vaccination against the SARS-CoV-2.

Discontinuing cardiovascular medications taken at admission during COVID-19 has been a controversial topic. Increased ACE2 receptor expression with RAAS blockade has been documented, which theoretically would favor SARS-CoV-2 entry into the cells. Nonetheless, other animal [22] and human studies [23] could not reproduce this upregulation of the receptor during treatment with RAAS blockade. Some authors warn about the harmful effect of RAAS blockers and advise its discontinuation to prevent poor outcome [14] while others claim to maintain these drugs until more evidence is available [15, 24]. The present data show that RAAS blockers are not harmful as seen in a recent Spanish study [25]. Only a prospective randomized study in patients free of the infection would provide evidence-based answers, which seems very difficult to undertake. In this regard, the investigators of the RASTAVI trial, which is currently randomizing patients with severe aortic stenosis who have indication for a percutaneous aortic prosthesis to ramipril or not, have shown that randomization to ramipril had no impact in the incidence or severity of COVID-19 [26].

Beta-blockers and statins are widely used due to their multiple beneficial effects in cardiovascular disease. In particular, statins may improve endothelial dysfunction, decrease expression of pro-inflammatory cytokines like interleukin-6 [27] and modulate the immune response at different levels, including immune cell adhesion and migration, antigen presentation, and cytokine production [28].
The current study results suggest that keeping cardiovascular related medication during COVID-19 is not harmful. Indeed, statins were found to be protective, which could be related to their pleiotropic effects. It has to be emphasized that this refers to medications the patient is already taking at admission and the present results do not support initiating these medications during hospital stays to enhance outcome.

Acute heart failure may be present in $23 \%$ of patients in their initial presentation for COVID-19 [6]. In the current cohort, acute heart failure was the most frequent cardiovascular event and showed a significant association with mortality. Results confirm the suspicions raised by previous works [29, 30]. Bearing this in mind, we recommend an active search of heart failure for its prompt diagnosis and treatment during COVID-19. However, we are aware of the difficulty of making a differential diagnosis between heart failure and respiratory failure in this setting.

There is available evidence of the occurrence of myocarditis secondary to SARS-CoV-2, confirmed by magnetic resonance and autopsy findings of inflammatory mononuclear infiltrate in myocardial tissue [31]. In the present cohort 2 cases of myocarditis were diagnosed and both required venoarterial extracorporeal membrane oxygenation as life support therapy.

With respect to acute coronary syndromes, it has been previously demonstrated the increased incidence in other viral infections like influenza $[10,32]$. Frequency of type I myocardial infarction of patients with COVID-19 is unknown. The true prevalence in this setting may be underreported given the logistical challenges associated with limited testing and cardiac catheterization laboratory availability in this scenario.

Another concern about the management of COVID-19 is to reduce as much as possible the incidence of life-threatening ventricular tachyarrhythmias. COVID-19 treatment includes the use of hydroxychloroquine and azithromycin, which have known potential to induce QT prolongation. Besides, lopinavir-ritonavir presents a possible "torsade de pointes" risk.

Despite the importance of ECG to detect lengthening of QT interval it was performed in only $56.7 \%$ of the cohort. Physicians taking care of COVID-19 patients may be unaware of arrhythmogenic capacity of commonly used medications in this disease, particularly if used in combination. As stated previously, it was herein considered that hydroxychloroquine, azithromycin and lopinavir-ritonavir prolongers of the QT interval. 


\section{Limitations of the study}

Some limitations have to be recognized. The protocol did not include troponin and B-type natriuretic peptide measurements that were done at the physicians' discretion, and a putative link between these parameters and the development of cardiac complications was not explored. Being the number of patients without ECG a limitation, it reflects the real-life practice in busy hospitals struggling with a massive admission of patients but having limited capacity and resources. The conclusions made here cannot be extrapolated to outpatients given that only patients admitted to the hospital were included. Finally, although the utmost care was taken to accurately apply our database, unintended mistakes cannot be ruled out. Nonetheless, to verify reliability of the gathered data 50 patient records were reviewed by an independent observer and only $0.04 \%$ variables were found to be incorrect. Moreover, all quantitative outliers (more than mean \pm 2 standard deviation) were checked by an independent observer.

\section{Conclusions}

Heart disease identifies patients with higher mortality, but it is not an independent predictor of death. Cardiovascular medications taken before admission are not harmful, statins being protective. The development of cardiovascular events is related to poor outcome.

\section{Conflict of interest: None declared}

\section{References}

1. Dong E, Du H, Gardner L. An interactive web-based dashboard to track COVID-19 in real time. Lancet Infect Dis. 2020; 20(5): 533-534, doi: 10.1016/S1473-3099(20)30120-1, indexed in Pubmed: 32087114 .

2. Guan WJ, Ni ZY, Hu Y, et al. Clinical characteristics of coronavirus disease 2019 in China. N Engl J Med. 2020; 382(18): 1708-1720.

3. Huang C, Wang Y, Li X, et al. Clinical features of patients infected with 2019 novel coronavirus in Wuhan. Lancet. 2020; 395(10223): 497-506.

4. Liang WH, Guan WJ, Li CC, et al. Clinical characteristics and outcomes of hospitalised patients with COVID-19 treated in Hubei (epicentre) and outside Hubei (non-epicentre): a nationwide analysis of China. Eur Respir J. 2020; 55(6), doi: 10.1183/13993003.00562-2020, indexed in Pubmed: 32269086.

5. Wang D, Hu Bo, Hu C, et al. Clinical characteristics of 138 hospitalized patients with 2019 novel coronavirus-infected pneumonia in Wuhan, China. JAMA. 2020; 323(11): 1061-1069, doi: 10.1001/ jama.2020.1585, indexed in Pubmed: 32031570.
6. Zhou F, Yu T, Du R, et al. Clinical course and risk factors for mortality of adult inpatients with COVID-19 in Wuhan, China: a retrospective cohort study. Lancet. 2020; 395(10229): 1054-1062, doi: 10.1016/S0140-6736(20)30566-3, indexed in Pubmed: 32171076.

7. Shi Yu, Yu X, Zhao H, et al. Host susceptibility to severe COVID-19 and establishment of a host risk score: findings of 487 cases outside Wuhan. Crit Care. 2020; 24(1): 108, doi: 10.1186/s13054-020-2833-7, indexed in Pubmed: 32188484.

8. Hemmat N, Ebadi A, Badalzadeh R, et al. Viral infection and atherosclerosis. Eur J Clin Microbiol Infect Dis. 2018; 37(12): 2225-2233, doi: 10.1007/s10096-018-3370-z, indexed in Pubmed: 30187247.

9. Kwok CS, Aslam S, Kontopantelis E, et al. Influenza, influenzalike symptoms and their association with cardiovascular risks: a systematic review and meta-analysis of observational studies. Int J Clin Pract. 2015; 69(9): 928-937, doi: 10.1111/ijcp.12646, indexed in Pubmed: 25940136.

10. Warren-Gash C, Smeeth L, Hayward A. Influenza as a trigger for acute myocardial infarction or death from cardiovascular disease: a systematic review. Lancet Infect Dis. 2009; 9(10): 601-610, doi: 10.1016/s1473-3099(09)70233-6.

11. Udell JA, Farkouh ME, Solomon SD, et al. Does influenza vaccination influence cardiovascular complications? Expert Rev Cardiovasc Ther. 2015; 13(6): 593-596, doi: 10.1586/14779072.2015.1044439, indexed in Pubmed: 25971953.

12. Guo T, Fan Y, Chen M, et al. Cardiovascular implications of fatal outcomes of patients with coronavirus disease 2019 (COVID-19). JAMA Cardiol. 2020; 5(7): 811-818, doi: 10.1001/ /jamacardio.2020.1017, indexed in Pubmed: 32219356.

13. Clerkin KJ, Fried JA, Raikhelkar J, et al. COVID-19 and cardiovascular disease. Circulation. 2020; 141(20): 1648-1655, doi: 10.1161/CIRCULATIONAHA.120.046941, indexed in Pubmed: 32200663.

14. Esler M, Esler D. Can angiotensin receptor-blocking drugs perhaps be harmful in the COVID-19 pandemic? J Hypertens. 2020; 38(5): 781-782, doi: 10.1097/HJH.0000000000002450, indexed in Pubmed: 32195824.

15. Vaduganathan M, Vardeny O, Michel T, et al. Renin-angiotensinaldosterone system inhibitors in patients with COVID-19. N Engl J Med. 2020; 382(17): 1653-1659, doi: 10.1056/NEJMsr2005760, indexed in Pubmed: 32227760.

16. Ponikowski P, Voors A, Anker S, et al. 2016 ESC Guidelines for the diagnosis and treatment of acute and chronic heart failure. Eur Heart J. 2016; 37(27): 2129-2200, doi: 10.1093/eurheartj/ ehw128.

17. Adler Y, Charron P, Imazio M, et al. ESC Scientific Document Group. 2015 ESC Guidelines for the diagnosis and management of pericardial diseases: The Task Force for the Diagnosis and Management of Pericardial Diseases of the European Society of Cardiology (ESC)Endorsed by: The European Association for CardioThoracic Surgery (EACTS). Eur Heart J. 2015; 36(42): 2921-2964.

18. Caforio ALP, Pankuweit S, Arbustini E, et al. Current state of knowledge on aetiology, diagnosis, management, and therapy of myocarditis: a position statement of the European Society of Cardiology Working Group on Myocardial and Pericardial Diseases. Eur Heart J. 2013; 34(33): 2636-48, 2648a, doi: 10.1093/ eurheartj/eht210, indexed in Pubmed: 23824828.

19. Huang I, Lim MA, Pranata R. Diabetes mellitus is associated with increased mortality and severity of disease in COVID-19 
pneumonia - a systematic review, meta-analysis, and metaregression. Diabetes Metab Syndr. 2020; 14(4): 395-403, doi: 10.1016/j.dsx.2020.04.018, indexed in Pubmed: 32334395.

20. Ferrario CM, Jessup J, Chappell MC, et al. Effect of angiotensin-converting enzyme inhibition and angiotensin II receptor blockers on cardiac angiotensin-converting enzyme 2. Circulation. 2005; 111(20): 2605-2610, doi: 10.1161/CIRCULATIONAHA.104.510461, indexed in Pubmed: 15897343.

21. Furuhashi M, Moniwa N, Mita T, et al. Urinary angiotensinconverting enzyme 2 in hypertensive patients may be increased by olmesartan, an angiotensin II receptor blocker. Am J Hypertens. 2015; 28(1): 15-21, doi: 10.1093/ajh/hpu086, indexed in Pubmed: 24842388.

22. Burchill LJ, Velkoska E, Dean RG, et al. Combination renin-angiotensin system blockade and angiotensin-converting enzyme 2 in experimental myocardial infarction: implications for future therapeutic directions. Clin Sci (Lond). 2012; 123(11): 649-658, doi: 10.1042/CS20120162, indexed in Pubmed: 22715807.

23. Campbell DJ, Zeitz CJ, Esler MD, et al. Evidence against a major role for angiotensin converting enzyme-related carboxypeptidase (ACE2) in angiotensin peptide metabolism in the human coronary circulation. J Hypertens. 2004; 22(10): 1971-1976, doi: 10.1097/00004872-200410000-00020, indexed in Pubmed: 15361769.

24. de Abajo FJ, Rodríguez-Martín S, Lerma V, et al. Use of renin-angiotensin-aldosterone system inhibitors and risk of COVID-19 requiring admission to hospital: a case-population study. Lancet. 2020; 395(10238): 1705-1714, doi: 10.1016/S01406736(20)31030-8, indexed in Pubmed: 32416785.

25. López-Otero D, López-Pais J, Cacho-Antonio C, et al. Impact of angiotensin-converting enzyme inhibitors and angiotensin recep- tor blockers on COVID-19 in a western population. CARDIOVID registry. Rev Esp Cardiol. 2021; 74(2): 175-182, doi: 10.1016/j. rec.2020.05.018.

26. Amat-Santos IJ, Santos-Martinez S, López-Otero D, et al. Ramipril in high-risk patients with COVID-19. J Am Coll Cardiol. 2020; 76(3): 268-276, doi: 10.1016/j.jacc.2020.05.040, indexed in Pubmed: 32470515.

27. Oesterle A, Laufs U, Liao JK. Pleiotropic effects of statins on the cardiovascular system. Circ Res. 2017; 120(1): 229-243, doi: 10.1161/CIRCRESAHA.116.308537, indexed in Pubmed: 28057795 .

28. Zeiser R. Immune modulatory effects of statins. Immunology. 2018; 154(1): 69-75, doi: 10.1111/imm.12902, indexed in Pubmed: 29392731.

29. Madjid M, Safavi-Naeini P, Solomon SD, et al. Potential effects of coronaviruses on the cardiovascular system: a review. JAMA Cardiol. 2020; 5(7): 831-840, doi: 10.1001/jamacardio.2020.1286, indexed in Pubmed: 32219363.

30. Inciardi RM, Adamo M, Lupi L, et al. Characteristics and outcomes of patients hospitalized for COVID-19 and cardiac disease in Northern Italy. Eur Heart J. 2020; 41(19): 1821-1829, doi: 10.1093/eurheartj/ehaa388, indexed in Pubmed: 32383763.

31. Siripanthong B, Nazarian S, Muser D, et al. Recognizing COVID19-related myocarditis: The possible pathophysiology and proposed guideline for diagnosis and management. Heart Rhythm. 2020; 17(9): 1463-1471, doi: 10.1016/j.hrthm.2020.05.001, indexed in Pubmed: 32387246.

32. Kwong JC, Schwartz KL, Campitelli MA, et al. Acute myocardial infarction after laboratory-confirmed influenza infection. N Engl J Med. 2018; 378(4): 345-353, doi: 10.1056/NEJMoa1702090, indexed in Pubmed: 29365305. 